\title{
BASIC CONCEPTS AND TERMS OF HORSE SPORTS
}

\author{
Nazarov S.U.
}

Acting Associate Professor, Department Of Sports Management, Institute Of Retraining And Advanced Training Of Physical Culture And Sports, Uzbekistan

\section{ABSTRACT}

This article provides information on the basic concepts and terms of equestrian sports in the form of short articles. This will increase the interest of young people in equestrian sports, strengthen their knowledge, enrich and develop the Uzbek language.

KEYWORDS:- Horse breeds, equipment, equipment, running, race, history, jockey, kupkari, manege, pedigree horse, horse passport, equestrian school, equestrian hurdles, equestrian, stables, sur-papah , competition-ippik, three wrestling, saddle-harness.

\section{INTRODUCTION}

Horses have long been a major source of support in mountainous and rural areas. Today, equestrian sports are gaining popularity around the world. It is well known that horses are not only a labor force but also bred for meat and milk. From their milk a healing girl is made. Horse blood is also used in the preparation of medicines and serums.

Horses were domesticated about 3,000 BC. The ancestor of the domestic horse is Tarpan, which once lived in the deserts of Europe and is now extinct. Horses are divided into heavy-duty, saltriding, light-weight (horse) and meat and mare breeds. Heavy-duty horses include Vladimir, salt horses, Karabayir in Uzbekistan, Lakay in Tajikistan and Akhal-Teke in Turkmenistan, and Orlov and Rus in Russia.

Cabinet of Ministers of the Republic of Uzbekistan 2017
In accordance with the Resolution No. 517 of 19 July "On measures for the integrated development of horse breeding and equestrian sports in 2017-2021", further development of the horse breeding industry in the Republic, breeding and breeding of sports horses , identified ways to ensure participation in sporting events, control episodic sustainability, as well as address issues related to the breeding and breeding of sport horses. Addressing these issues also requires children to be provided with important information to increase their knowledge of the basic concepts and terms that are widely used in equestrian sports in order to engage them in equestrian sports. We believe that the concepts and terms of equestrian sports will help the younger generation to further strengthen their knowledge of physical culture and sports, to enrich and develop the Uzbek language.

AKHALTAKA HORSE BREED (axaltekinskaya breed) is the oldest horse breed. The most 
ancient breed of riding horses, mixed with Nesey and Parthian horses. The homeland of the AkhalTeke horse breed is the Akhal oasis (Turkmenistan), located in the northern foothills of the Kopet-Too ridge, inhabited by the Teke Turkmen tribe. Typically, these breeds are very large (up to 155-160 cm in height), distinguished by their slender body, elegance and grace. They have tall legs, a slender but strong body structure. In 1935 he took part in the AshgabatMoscow horse race and covered $4300 \mathrm{~km}$ in 84 days. crossed the road. Successfully participates in classic equestrian sports. The ancestors of the Akhal-Teke horse breed played an important role in the formation of the Arabian breed in the IV-VI centuries BC. Later, it was used to breed traken, buckwheat, grain, eagle and other thoroughbred horses.

THE STATE BREEDING BOOK is a collection of information about horses that incorporates pedigree traits.

Doping control - all horses in international and other major competitions are subject to a special commission inspection of banned drugs (doping). Horses tested for doping before the start will not be allowed to compete. If at the end of the race, doping is detected in the horse in which the athlete participated, the athlete will be disqualified. Doping control has been included in all Olympic programs since 1972.

JOCKEY (visual jockey) - a skilled rider in horse racing; horse training specialist, trainer.

COMPETITION, equestrian competition (French: Concours Hippique - equestrian competition) - in the broadest sense, any equestrian competition. In our country - competitions on overcoming various obstacles (from 6 to 18).

KUPKARI is the national equestrian sport of the peoples of Central Asia (Kazakh, Kyrgyz, Tajik, Uzbek and Karakalpak). Kupkari means "Wolf". In ancient times, nomads took a warrior as a toy and chased him on the most agile horses. Later, the body of a kid was replaced by a fighter. The goal is to lift the kid's body off the ground and take it to its gate. The rule of the game is that the game involves two teams of 5 people each (1 reserve). The playground is $400-500 \mathrm{~m}$ long and 20-30 m wide. (usually in the equestrian arena of the tribunal). There will be two gate flags on the side of the field. Diam to the center of the field to place the kid's body before the game starts. $3 \mathrm{~m}$. a circle is drawn. At the referee's signal, the teams are $10 \mathrm{~m}$ from the center circle. they have to go a long way and clear a number. The game lasts 15 minutes. If a draw is observed, another 15 minutes will be added. In case of violation of the rules of the game, the kid (the rider with the body of the kid) is out by the referee and the game is restarted in front of the place where the rules of the game are violated. An unruly rider who violates the rules of the game will be suspended for 5 minutes by the referee (cannot be replaced).

MANEJ (French manege) is a special open or closed place where horses are trained or riders and cavalry are trained. Typically $20 \times 40 \mathrm{~m}$. or $20 \times 60 \mathrm{~m}$. (minimum $10 \times 20 \mathrm{~m}$ ) is a rectangle.

BREEDING HORSE - a horse of pedigree (pedigree) belonging to a particular breed and registered in the State Pedigree Book as a pedigree horse.

HORSE PASSPORT - contains information on the pedigree and pedigree of sport horses, pedigree, pedigree value, vaccines against infectious diseases, the results of laboratory tests and diagnostic tests document received.

Equestrian sports - equestrian competitions. Main types: wheelchair training; competition (overcoming an obstacle); running - horseback riding in the manege (based on allura exercises), field tests (steeplechase, cross, road traffic) and overcoming obstacles; run; horse hunting; volleyball (equestrian exercises) and others were 
included in the program of the 1900 Olympics and the 1994 Asian Games. World and European Championships have been held since 1953. The International Equestrian Federation (FEI) was founded in 1921 and now unites 134 national (2006) federations. In 1993, the Equestrian Federation of Uzbekistan was established. Since 1997, the national team of Uzbekistan has been independently participating in international competitions. M. Ismailov, V. Dvoryanikov, Yu. Kovshov, A. Tankovs gained great fame.

EQUESTRIAN SCHOOL is the main form of organization of equestrian sports, along with equestrian clubs and sections. The equestrian school teaches horseback riding, trains athletes in a variety of equestrian sports, dresses and trains equestrian sports, and organizes equestrian competitions.

HORSE SPORTS Types of barriers - barriers can be: high and steep (for example, barns, stone walls, fences, etc.); high-wide-stations, oxers, etc ; broad-shouldered. Consists of 2 or 3 separate barriers, 1 or more of which are horses

Obstacles that exceed 2 times are called systemic. SPORTS HORSE - a horse that participates in various equestrian competitions involving horses.

HORSE OWNERS are legal entities or individuals who have the right to own a horse.

OTCHOPAR (Greek hippodromos - hippos - horse and dromos - a place for running, jogging), a complex for testing equestrian competitions and racehorses; the organization that organizes them. Modern horse-drawn carriages are modeled on ancient Greek horse-drawn carriages. The length of the corridors is usually 2000-3000 m. The main corridor is covered with tar-impregnated black soil (for testing and training of racehorses and racehorses). There will also be a local, wood-paneled (horseback riding) drive. The curves of the treadmill are slightly raised $12-15 \mathrm{~cm}$ from the outside. The equestrian center has a variety of service facilities: a stable, a blacksmith's shop, a mobile veterinary clinic, and locker rooms. Horseback riding is sometimes held in cross-country athletics. The following types of modern horses are known and popular: Lexington (USA), New Market, Epsomsk (UK), Vienna, Lonshan (France), Pardubisk (Czechoslovakia), Madrid (Spain), Moscow (Russian Federation).

HORSE - a place that plays a key role in the storage of horses, the construction of the stable, ventilation and cleanliness must meet the special rules of storage of horses. For horses, good lighting and fresh air make them feel good. Taking good care of your horses will keep them healthy and able to work. It also includes taking good care of the horses, treating them well, and following the rules of riding. The daily amount of fodder (ration) for a horse is about $5 \mathrm{~kg}$ added to the cut straw mixture. oats and the composition consists of the same amount of hay. The horse is fed 3 times a day (morning, afternoon and evening).

SYUR-PAPAX (equestrian basketball) is an equestrian sport. It is widely developed in Azerbaijan. It requires agility, speed, and masterful maneuverability, precision, and great courage on the part of the rider. Game length $300-400 \mathrm{~m}$. will be held on the racetrack. $3 \mathrm{~m}$ to the beginning and end of the field. column diam. $50 \mathrm{~cm}$. the ring is fastened. $5 \mathrm{~m}$ around the column. a penalty line is drawn (another $1.5 \mathrm{~m}$ inside).

TASHKENT OTCHOPARI is a sports facility where national and international equestrian competitions, various ceremonies, kid riding and horse training are held. Official equestrian competitions in Tashkent were first held in the early 20th century. It was built in 1976 in Tashkent, the largest equestrian center in the country (until 1976, the equestrian center was 
located near the Kuylik district of Tashkent). Tashkent equestrian center is located in Chilanzar district (formerly A. Ikramov district) and has an area of 70 hectares, designed by architects: RU Asanov, EIGusarova. Tashkent equestrian center has equestrian, horse racing, horseback riding, running, testing and cooling of horses, training grounds, barrier corridors, veterinary infirmary (hospital), quarantine rooms, swimming pool and others. The Tashkent Equestrian Center hosts competitions, equestrian exercises and other ceremonies.

THREE WRESTLING (troebore) is one of the equestrian competitions. Competitions are held in the manege, on the field and over obstacles, for three days without a break. The first day of competitions - $60 \times 20 \mathrm{~m}$. on the art of horseback riding in a large manege (basic allure, turns, stops in the prescribed manner), the second day 23-34 $\mathrm{km}$ of 5 different difficult roads, overcoming obstacles without stopping to the finish line On the third day, you will have to overcome difficult obstacles ("Red Wall", "Double Barrier", "Oxer", "Stasonat", "Elephant Barriers", "Amsterdam Gate", etc.). they compete. During the winter, there are two indoor wrestling events (no hurdles competitions).

EGAR-JABDUQ (upryazh, sbruya) - a device for managing horses and oxen, deer, dogs and other animals and using their power in work (loader, oxen, cart, agricultural implements). A horse's bridle consists of a saddle harness, a bow, a slotted belly button, a slit, a belt around the waist and chest, a jug, and a reins. A saddle is the basic saddle of a horse. horse breeding and equestrian sports in 2017-2021". Tashkent-July 19, 2017.

2. Mavlonov O. BIOLOGY (ZOOLOGY) -T .: National Encyclopedia of Uzbekistan. 2017.

3. Nematov B.I., Nazarov S.U. Concepts and terms related to equestrian sports. Tashkent2021

4. Kudin A.N. Physical culture and sports. Malaya Encyclopedia. - Moscow. FIS, 1982.

\section{ReFERENCES}

1. Resolution of the Cabinet of Ministers of the Republic of Uzbekistan No. 517 "On measures for the integrated development of 